\title{
Implicancias profesionales del nuevo relato cultural-penal juvenil. Consideraciones desde Argentina.
}

\author{
Osvaldo Agustín Marcon
}

\begin{abstract}
Resumen
Argentina ingresa a la lógica de la responsabilización penal juvenil con cierto retardo en relación a los demás países latinoamericanos. Sin embargo, dicha demora sirve para el propio país, pero también para no dejar cristalizar las distintas prácticas profesionales atravesadas por tales matrices. Tanto el relato del 'amor por los niños' como el del niño 'sujeto de derechos' puede ser utilizado como perfecta herramienta de control social que creen ficciones en relación al tema. El 'amor' para ser tal requiere mucho más que lágrimas, y el 'derecho', para ser tal, requiere mucho más que su formulación jurídica. El ejercicio profesional camina constantemente con el riesgo de caer en alguna de las reducciones conservadoras. Si bien se parte del caso argentino, la discusión se enriquece en la perspectiva latinoamericanista.
\end{abstract}

\begin{abstract}
Argentina entered the logic of juvenile criminal responsability in some delay in relation to other Latin American countries. But this delay is for the country itself but also to not let various profesional practices crystallize traversed by such matrices. Both the story of 'love for children' as 'subject of rigts', can be used as a perfect tool of social control that create fictions in relation to the subject. The 'love' to be so requires much more tan tears and the 'rigth' to be such, requieres more tan its legal formulation. Constantly practice walking with the risk of falling into one of tvo conservative cuts. While part of the Argentine case, the discussion is enriched in the Latin American perspective.
\end{abstract}

\section{Desarrollo del artículo}

\section{La cuestión que nos ocupa}

Con asiduidad, desde los colectivos profesionales que integran los distintos servicios públicos se opina respecto de la calidad de la intervención. Esto incluye, en particular, la discusión respecto de los dispositivos instituidos para intervenir en relación a la niñez socialmente excluida que, además, ha ingresado en el campo del conflicto penal. Distintas consideraciones tienen lugar, incluyendo aspectos políticos, presupuestarios, organizacionales, etcétera, pero pocas veces se fija la mirada en el efecto reproductor que la acción profesional tiene en sí misma, más allá de los resultados obtenidos en relación al caso en particular que circunstancialmente la ocupa. Las decenas, cientos o miles de prácticas cotidianas no siempre son dimensionadas en todo su potencial sino que, por el contrario, suelen ser codificadas residualmente: se hizo y se obtuvo lo posible en relación al problema abordado. No se advierte -creo- lo que esto significa en términos de reproducción más allá del asunto abordado.

Sin embargo, y dado que el profesional integra un escenario complejo, todos sus pasos tienen algún grado de eficacia en distintos terrenos. De un modo u otro su acción produce subjetividad, más allá de aquél o aquéllos a quienes está explícitamente dirigida la acción. No pocas veces, mas aun en el contexto de profundas crisis político-partidiaria que afectan a la mayoría de los países latinoamericanos, los dirigentes políticos reclutan, una vez llegados a la función pública, a sus propios ejecutores políticos de entre los profesionales ya existentes en las distintas estructuras. Y éstos, como sabemos, se ajustan en gran medida a la exigencia de aquel dirigente pero no pueden evitar expresar aspectos del nivel de conciencia profesional existente en sus respectivos colectivos.

Así dadas las cosas es relevante entonces prestar atención al modo en que operan determinados supuestos profesionales ante la encrucijada que nos ocupa, en la que se advierte la posibilidad de avanzar hacia nuevas matrices de intervención, pero también -no podemos ignorarlo- se presentan otros caminos más o menos perceptibles de modo consciente. Algunos de ellos se caracterizan por viejas prácticas, mientras que otros son proclives a confundir nuevas prácticas con meros retoques exteriores. Tales supuestos, 


\section{Sorvita}

como decíamos anteriormente, tienen un importante efecto reproductor que puede tanto favorecer como obstaculizar transformaciones.

Del amplio abanico de supuestos profesional identificables, interesa destacar aquí los organizados en torno a dos polos que se repelen mutuamente pero coinciden en que ambos lentifican el avance en profundidad hacia formas de intervención compatibles con el paradigma vigente, resumido bajo la aspiración de una Protección Integral sobre la Niñez o, dicho de un modo más genérico, vigencia integral de los Derechos Humanos del Niño. Hemos de hacer notar, no obstante, que tanto los que intentamos subrayar aquí como todos, los otros operan en el contexto de una profunda Turbulencia civilizatoria, y que siendo ese el contexto es necesario advertir las dificultades, tanto para valorar los supuestos en sí mismos como para pensar en su reconfiguración. Son, claro está, supuestos problemáticos, pues si así no fuera ningún llamado de atención sería necesario. Y en tanto problemáticos, debemos admitir, de antemano, que desconocemos las profundidades de su naturaleza íntima. Podemos, apenas, esbozar nuevos supuestos a ratificar, corregir o rechazar definitivamente.

\section{El primero de los polos: ¿es legítimo intervenir 'por amor a los niños'?}

Nadie duda que la expresión 'amor por los niños' remite a una de las reservas humanas más preciadas a la que obviamente se debe preservar de toda mella. No nos referimos a dicho sentimiento en cuanto tal ni a las acciones que él genera en la sociedad. Sí nos ocupamos, aun con las dificultades que implica establecer esta diferencia, de las formas que éste suele adquirir al momento de transitar por distintos dispositivos institucionales, de naturaleza penal para la exposición que nos ocupa.

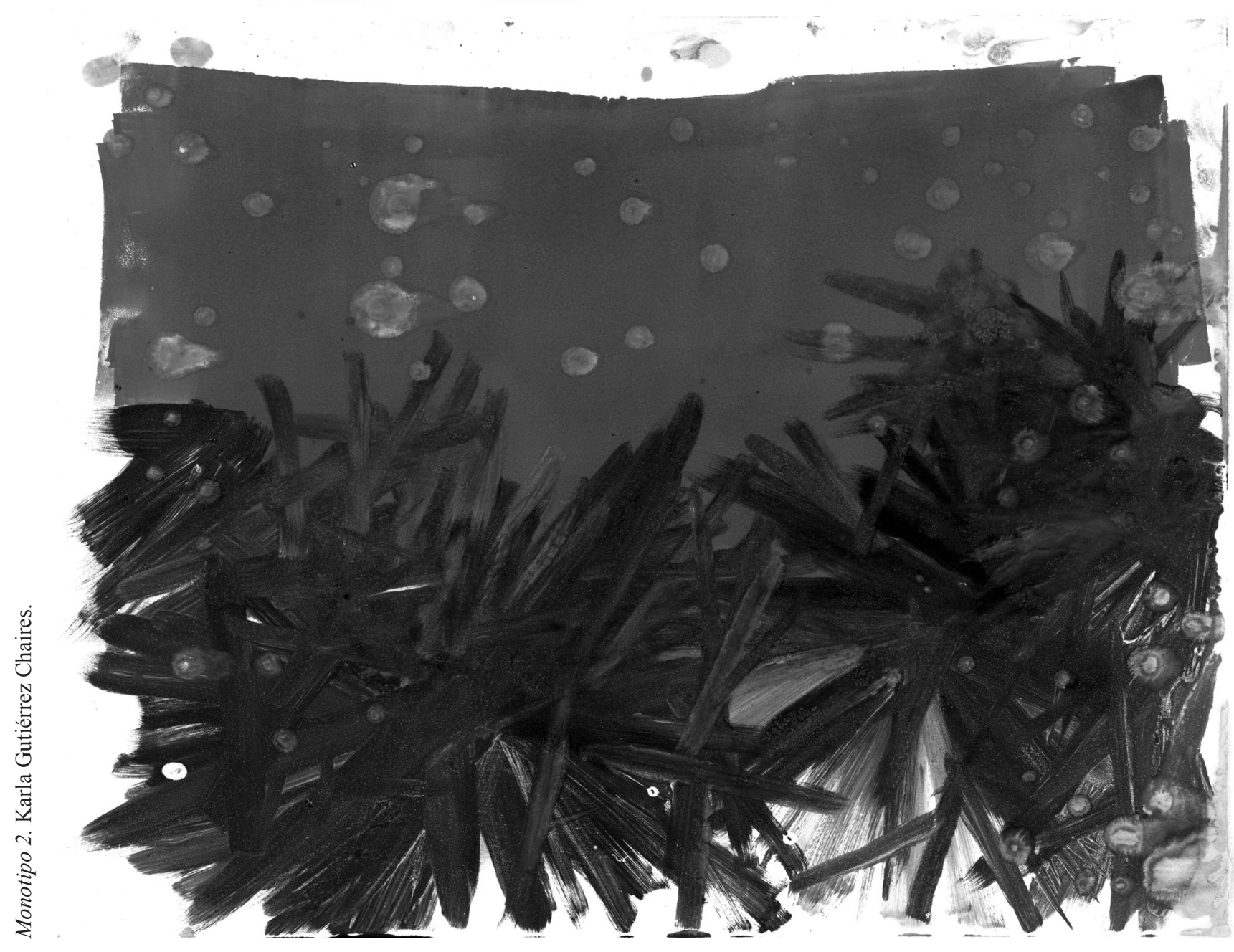


Trabajar desde el Estado en beneficio de la niñez pareciera traer consigo, como condición de calidad, este amor al que intentamos referirnos. Esto suele ser así, pero también es cierto que las más de las veces es ese mismo amor el que va a contramano del funcionamiento judicial como tentativa de restauración de límites, de formas de efectivización de la socialización total o parcialmente fallida. Los juzgados (o tribunales específicas en cuyo marco algunas conductas profesionales pueden constituirse en obstáculos antes que en facilitadores.

Este tipo de impedimentos no aparecen con asiduidad en las declaraciones importantes, en los cuerpos teóricos desarrollados académicamente o en artículos publicados en revistas científicas. Emergen, más bien, en los vericuetos cotidianos de los distintos dispositivos institucionales. Allí se advierte, creo, el desarrollo de estrategias que por asentarse en la afectividad tienden a colocar en un segundo plano la eficacia de los Derechos Humanos (de niñas y niños, en este caso). Esta eficacia, recordemos, no tiene su fundamento en la voluntad de algún operador de turno, pues debe imperar por sí misma. Sin embargo, ciertas formas del instinto protector (si es que esto existe) parecen enseñorearse en las escenas, no codificadas como formas de construcción de ciudadanía sino como muy personales decisiones de proteger a tal o cual niño. No pocas veces esta tendencia tiene como efecto una tendencia a escindir las intervenciones profesionales: a un lado quedan los que se ocupan de 'lo jurídico' y a otro lado los que se ocupan de 'lo interdisciplinario' como si esto último no debiera formar parte de un continuo con lo primero y viceversa.

Estaremos de acuerdo en que esto no es nuevo. Se trata, precisamente, de una inclinación profesional que nos mantuvo durante un siglo llevando adelante lo que hoy ya aceptamos como expresión de cierta tutela-represiva (parafraseando en esto al argentino García Méndez). Quizás tendríamos que advertir, como profesionales, que posiblemente ese siglo haya sido un siglo perdido. Esto no invalida loables esfuerzos identificables durante tal periodo, pero esos méritos no deberían impedirnos ver que si las intervenciones no se hubiesen agotado en, pensando en los mejores de los casos, insuficientes formas de trabajar con los niños en la institución, esta necesidad de dar un enorme salto no estaría hoy presente. Si progresivamente hubiésemos avanzado en lo teórico y lo instrumental, tendiendo a la universalización de tales avances, mas aun en las intervenciones no apoyadas en la privación de libertad ambulatoria, se hubiese generado una situación de hecho que no justificaría discutir hoy el paso -en ocasiones traumático- de una institucionalidad a otra aún por construir. Necesitaríamos en cambio, apenas, ajustar la normatividad legal, por presentarlo a título de ejemplo. $\mathrm{El}$ amor de muchos no ha sido suficiente, e insistimos en que no está esto dicho de un modo peyorativo en relación a tal sentimiento, sino en orden a señalar la necesidad de que ese amor se exprese, contundentemente, en construcción de ciudadanía. Es decir, que siga un camino mucho más esforzado.

Vale preguntar, creo, si no hemos perdido cien años en el disfrute de una única perspectiva (la nuestra) sin hacer demasiados esfuerzos a favor de la diversificación; incorporando como un elemento estable y extendido, por ejemplo, la perspectiva del niño. Y como aquí estamos pensando en la conflictiva dimensión penal, hemos también de decir que posiblemente no sea sólo el goce de nuestra perspectiva sino el disfrute de importantes sectores sociales que no pueden pensar una reacción estatal ante el delito que no sea la externalista; es decir, aquélla que valora desde afuera lo sucedido en nombre del denominado (y defendible) Derecho Penal de Acto. Pero sucede que se ha dado cierta ontologización de este modo de intervenir, obturando posibilidades de avance en general y en particular posibilidades de avance en relación a la intervención sobre niños y niñas que ingresan en un campo de conflicto penal. Desde fuera de ese niño, y desde el lugar de la fuerza estatal, se dice qué conviene y qué no. Se trata, claro está, de una cuestión ideológica actualmente operante. No pensamos aquí solo en quienes exhiben variables niveles de odio hacia jóvenes de sectores socialmente excluidos sino también en profesionales, jueces o legisladores sinceramente posicionados a favor de la niñez, pero disfrutando de la tranquilidad de conciencia que suele dar la mirada externa al niño, con baja capacidad de interpelación ante los distintos poderes.

Nos referimos a los Poderes con mayúsculas, es decir, a los Poderes del Estado. Pero también a los significativos poderes de ciudadanos o ciudadanas que en las grandes ciudades de Argentina están siempre listos o listas para llamar por teléfono a un medio de comunicación exigiendo 'hagan algo' ante todo hecho penal que involucra a niños como supuestos autores. Se trata, usualmente, del poder que no reclama 'hacer algo' a partir de la complejidad del problema sino que en muchas ocasiones ese 'algo' puede traducirse en exigencia de una nueva ficción a partir del encierro del 
joven en cualquier espacio, físico o no. Ese poder con minúsculas no pocas veces se transforma en Poder con mayúsculas, y de alguna manera está bien que así sea. Pero ya no está bien que los profesionales partan raudos a 'hacer algo' sobre la base una notoria precariedad teórica e instrumental, pensada inclusive desde muchas Unidades Académicas para otro tipo de espacios, para otras problemáticas, cargando así con todo el peso del 'siglo perdido' que en Argentina significó la vigencia de la Ley de Patronato del Estado desde 1919 hasta 2005. Perdido por lo anteriormente dicho: el encierro tranquilizó tanto que trocó en aletargamiento profesional que no puede ser dejado atrás con facilidad.

Es en este marco que podríamos pensar si eso de lo que hablamos de este punto es realmente amor $\mathrm{u}$ otra cosa, tal como por ejemplo solemos preguntarnos ante casos de violencia conyugal. ¿Qué construcción es esa, realmente? De Todos modos, y sin responder a tan difícil cuestión, permitámonos pasar al otro extremo en tensión, en ocasiones puesto en el lugar de la omnisciencia.

\section{El segundo de los polos: ¿es factible proteger penando?}

Aunque obtener confesiones en este sentido es muy difícil, muchos sospechamos que en el imaginario profesional interdisciplinario unas profesiones se consideran a sí mismas portadoras de un saber totalizante, capaz de dar cuenta de toda la realidad. Aún cuando se acepta la necesidad de otras miradas es común que algunas (o algunos profesionales) crean estar en condiciones de gritar “¡Eureka!” ante las situaciones a las que nos referimos. Este grito bien puede ser dado por cualquiera de las disciplinas proclives a brindar amor antes que acciones ajustadas a las teorías que constituyen su razón de ser. Pero lo usual es que este grito sea dado con mucha más fuerza por las disciplinas vinculadas a los aspectos positivizados de los Derechos Humanos.

No pocas veces este grito es dado en abierta oposición con los postulados de las demás profesiones, atravesadas como decíamos por los efectos del 'siglo perdido'. Las Ciencias Jurídicas, inclusive, se postulan para cubrir los espacios todavía no resueltos por aquéllas. En este marco, por ejemplo, se parte todavía de ideas según las cuales el viejo Derecho de Menores es paradójicamente una rama Menor del Derecho. Si cada una de estas caracterizaciones (viejo y menor) son letales para dicha disciplina, tanto más lo son ambas sumadas entre sí.
Pero sucede que para cubrir dicho envejecimiento, y ante la necesidad de dar respuesta a las exigencias del nuevo orden doctrinario, se apela rápidamente a los recursos desarrollados para el campo de los sujetos mayores de edad (Derecho Penal de Mayores) sin abrir instancias críticas de ningún orden, sea en relación a la calidad de dicho sistema aplicado sobre la poblaciónobjetivo originaria (sujetos mayores de edad), o sea en relación a lo que significa trasladar mecánicamente tales procedimientos al campo de la intervención sobre jóvenes de los que se presume han cometido delitos. En suma podríamos plantear que también para el campo jurídico el Siglo Perdido deja sus lecciones.

'Derechos en lugar de amor' podría ser la consigna que un imaginario contendiente levanta desde este polo frente al polo anterior. Tratemos de, como se dice metafóricamente por esta zona de Latinoamérica, "separar la paja del trigo". Y sabemos que "el trigo es bueno, ya lo sabemos, pero también lo es la paja aún cuando no para fabricar pan". Letras más, letras menos, concluye nuestro beligerante imaginario en lo que progresivamente tiende a aceptarse en toda la República Argentina y en gran parte de Occidente: los niños que atraviesan por situaciones de riesgo o abandono (es decir, que son víctimas de la cuestión social) deben ser objeto de intervención desde el Poder Ejecutivo mediante sus políticas específicas. Y los jóvenes de los que se presume han cometido delito deben ser objeto de intervención del Poder Judicial aún cuando éste se apoye en el Ejecutivo para llevar a la práctica las medidas que imponga.

Pero ¿cómo ha de intervenir ese Poder Judicial en relación a los jóvenes de los que se presume han cometido delito? Estableciendo una base que queda fuera de discusión: con las mismas garantías substanciales y procesales que respeta para los sujetos mayores de edad en análogas situaciones. Claro está que -se admitesobre esta base deben constituirse especificidades, con lo que aparece la idea de una Justicia Penal Juvenil. Esta concepción toma postulados universales, tales como la idea de garantizar el denominado debido proceso; pero simúltaneamente tiende, ante las distintas encrucijadas, a resolverlas mediante la universalización de formas operativas vigentes en la Justicia Penal de Mayores. Así, se presentan serios obstáculos para desarrollar una lógica propia. Una vez más, como ha sucedido en múltiples campos de conocimiento y de intervención, el método antecede al objeto, lo moldea sin tenerlo 


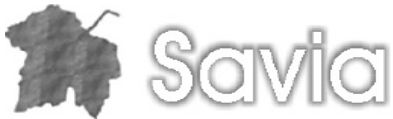

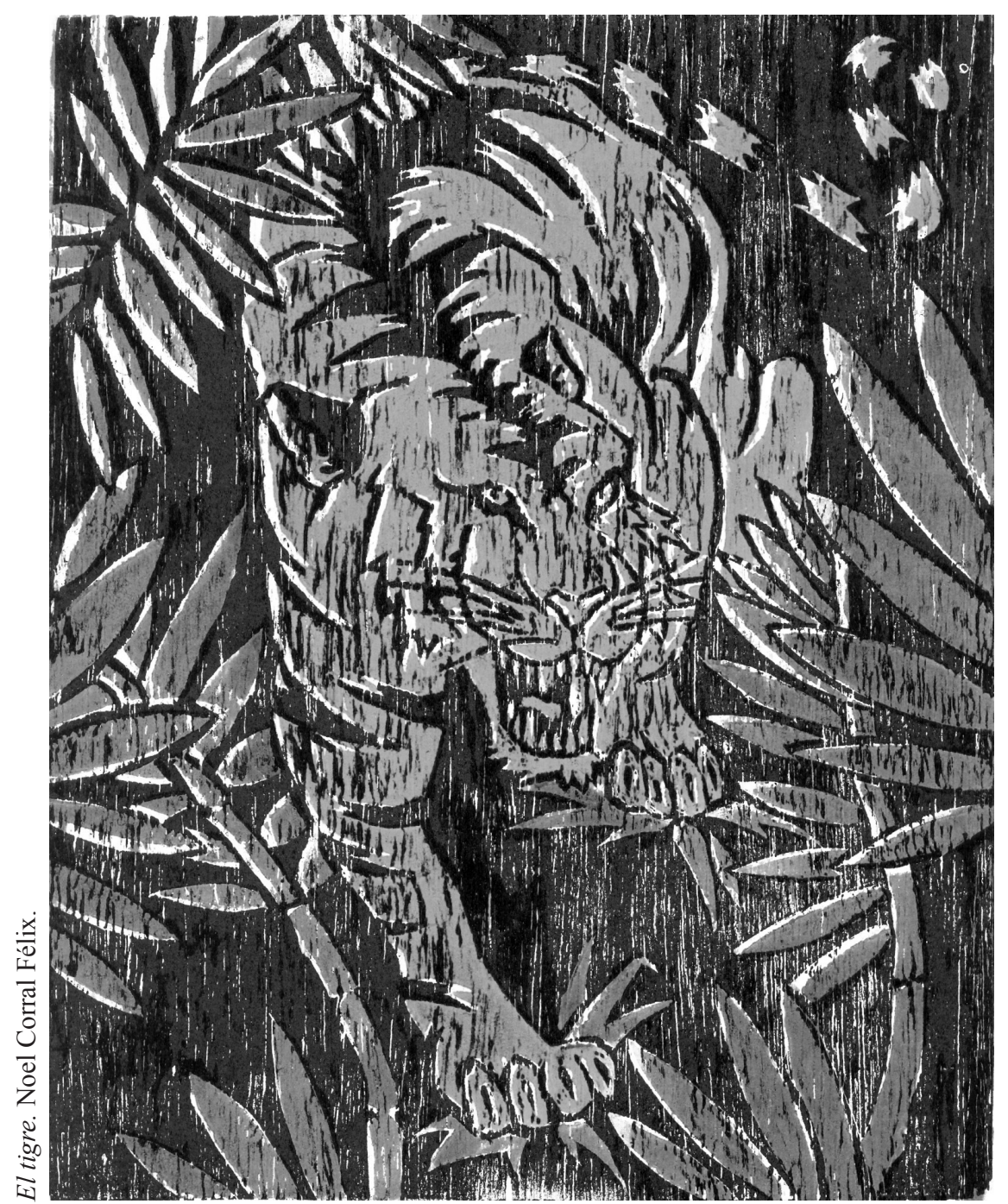

en cuenta, algo así como sentarnos en una mesa de restaurante y, dado que encontramos cucharas en la mesa, creernos obligados a almorzar sopa.

Ahora: tomando un aspecto clave advertimos que por este camino se acepta como natural que la pena coadyuva por sí misma todo proceso de construcción de responsabilidad en el joven. Se prioriza aquella perspectiva externalista a la que nos refiriéramos con anterioridad, y que encuentra dificultades para incorporar la perspectiva del sujeto como constitutiva del problema deteriorándose, así la especificidad (o la especialidad) que se espera en este tipo de intervención. Los condicionamientos epistemológicos son importantes.

Tenemos entonces cierta tendencia al raquitismo en la implementación que bien podemos sospechar no deviene de tal fase sino de la propia concepción originaria, como si más bien fuera intrínseca a la propia posición hegemónica. Se prioriza por esta vía la vigencia que siempre son postergadas. Para más adelante suele quedar la creación de cargos específicos (Profesionales Especializados, Fiscales Especializados, Defensores Especializados, Segundas Instancias Especializadas, Personal de Contacto Especializados, etcétera) y, con ello, se demora o suspende la discusión que podría dar lugar al desarrollo teórico y metodológico. En este marco generalmente cada caminante hace su camino, pero no están presentes los necesarios trayectos de formación específica. El raquitismo teórico hace presente los fantasmas del siglo perdido, pues como parte de las postergaciones persisten: 


\section{落 Sonta}

- Policías no preparadas eficazmente para tomar contacto con esta problemática desde una perspectiva profundamente enraizada en la Teoría de los Derechos Humanos.

- Instituciones que oscilan entre el "Paradigma amoroso" y el "Paradigma penitenciario".

- Estrategias defensivas copiadas de juicios penales a mayores, cuya lógica colisiona con otras disciplinas que promueven una conexión con el hecho de mayor calidad.

- Sentencias en las que se advierten dificultad para integrar los componentes disciplinares en un corpus con respetable densidad conceptual. Profesionales con dificultades para adecuar su formación de base al ámbito de los Derechos.

Advertimos cómo distintos aspectos tienden a coincidir en ambos extremos, aún cuando éstos se repelen entre sí por lo que:

\section{Señalamientos ante ambos polos}

Marco Aurelio González Berendique, Profesor Titular de Criminología en la Universidad de Chile, se refiere a aspectos históricos de la pena y luego, con el transcurso del tiempo, a su pretenso reemplazante: "el tratamiento". Pero y ante el dominio de este último recuerda que con cierta resignación la finlandesa "profesora Inkeri Anttila pide terminar con la 'hipocresía del tratamiento' y aludir explícitamente a castigo bajo condiciones de humanidad" (González Berendique, M., 2004:20). Estaríamos, con la idea de tratamiento, ante una expresión de aquel amor al que nos referíamos, expresado en el esfuerzo por reemplazar la idea de una pena lisa y llana por la idea de un tratamiento que, así, tranquiliza mucho más.

La lógica penal juvenil actual propone un camino que parece evitar el ocultamiento al que refiere Anttila, pero propone volver a la sanción penal, de un modo especial (penas distintas de los adultos) siguiendo, al fin y al cabo, la matriz punitiva que en tales términos es no responsabilizante, ante el supuesto según el cual la pena re-educa.

Vale preguntar ahora ¿hasta qué punto tanto ese amor como ese externalismo penal están en condiciones de promover la autonomía del sujeto, valor indiscutible en el contexto actual? ¿No convendría pensar en una re-distribución de responsabilidades que promueven identidades asentadas en la necesidad de co-responder por lo actuado? Al respecto Claus Roxin, Catedrático de Derecho Penal en la Universidad de Munich, dice: "Una pena que pretende compensar los defectos de socialización del autor sólo puede ser pedagógica y terapéuticamente eficaz cuando se establece una relación de cooperación con el condenado. Una 'socialización forzosa' no tendría perspectiva de éxito. (Roxin, C., 1997:95).

Quizás también sea necesario situar la respuesta penal, ¿dónde? En Latinoamérica. Y a Latinoamérica en un contexto de Estados-Nación que afrontan profundos desafíos civilizatorios tal como marcábamos al inicio, sean éstos propios de la Segunda Modernidad, Modernidad Líquida, Sobremodernidad o Modernidad Tardía, entre otras categorizaciones discutidas en el campo de las Ciencias Sociales. Posiblemente se imponga la necesidad de superar la mera vigilancia y la mera sanción como recursos, pues ya no se corresponde con los Estados vigentes, y mucho menos con la necesidad de dejar atrás la época de las sociedades belicistas en las que si la pena cumple una función pedagógica precisa: formar física y simbólicamente hombres guerreros.

Es necesario, entonces, combinar la visión externa con la perspectiva de los sujetos. Roxin dice: “(...) una vivencia expiatoria(...) constituye un acto moral autónomo de la personalidad, que no puede imponerse a la fuerza y que, por lo demás, puede ser motivado muchísimo mejor por una pena que no retribuya, sino que ayude" (Roxin, C., 1997:85).

\section{Bibliografía:}

González Berendique, M. (2004). Configuración y desfiguración del castigo. En: Figueredo Dias, J. y otros. El Penalista Liberal. Buenos Aires: Hammurabi.

Roxin, G. (1997). Derechos Penal. Parte General, Tomo I. Trad: Diego-Manuel Luzón Peña. Madrid: Civitas.

\section{Otra bibliografía consultada:}

Bauman, Z. (2003). Modernidad líquida. Buenos Aires: Fondo de Cultura Económica.

Bourdieu, P. (2003). La dominación masculina. Trad. Joaquín Jordá. Barcelona: Anagrama.

Demaría, V. y otros. (2004). No sólo de pan: Reflexiones sobre ciudadanía e infancia desde la perspectiva de la CIDN. San Juan. Puerto Rico: Universidad Nacional de San Juan. 


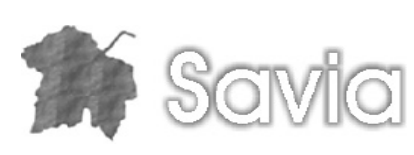

David, P. (2003). Sociología criminal juvenil. Buenos Aires: LexisNexis-Depalma.

Faleiros, V. (2004). Trabajo social e instituciones. Buenos Aires: Hvmanitas.

Foucault, M. (1980). La verdad y las formas jurídicas. Trad. Enrique Lynch. España: Gedisa.

García Méndez, E. (2001). Infancia y Adolescencia. De los derechos y la justicia. $2^{\mathrm{a}}$ ed. México: UNICEF.

Giddens, A. (1999). Consecuencias de la modernidad. Trad. Ana Lizón Ramón. Alianza Editorial.

Puebla, M. (2000). La clínica de la vulnerabilidad. San Juan, Puerto Rico. Universidad Nacional de San Juan.

Rozas Pagaza, M. (2001). La intervención profesional en relación con la cuestión social: el caso del Trabajo Social. Buenos Aires: Espacio Editorial.

Scarzanella, E. (2003). Ni gringos ni indios. Inmigración, criminalidad y racismo en la Argentina 18901940. Trad. Irene Theiner. Buenos Aires: Editorial Universidad Nacional de Quilmes.

Wacquant, L. (2000). Las cárceles de la miseria. Trad. Horacio Pons. Buenos Aires: Manantial. 